ISSN: 1410-8917

Jurnal Kimia

-Sains \&

Aplikasi

e-ISSN: 2597-9914
Jurnal Kimia Sains dan Aplikasi Journal of Scientific and Applied Chemistry

Journal homepage: http://ejournal.undip.ac.id/index.php/ksa

\title{
Antimicrobial Activities of Synthesized Silver Nanoparticles using Ethanol and Water Extract of Mirabilis Jalapa
}

\author{
Tunas Alam ${ }^{\mathrm{a},{ }^{*}}$, Frida Octavia Purnomo ${ }^{\mathrm{b}}$, Asbar Tanjung ${ }^{\mathrm{c}}$ \\ ${ }^{a}$ Department of Pharmacy, STIKes Prima Indonesia, Bekasi, Indonesia \\ ${ }^{\mathrm{b}}$ Department of Pharmacy, Faculty of Sciences and Technology, Binawan University, Jakarta, Indonesia \\ ${ }^{\mathrm{c}}$ Department of Medical Laboratory Technologist, STIKes Prima Indonesia, Bekasi, Indonesia
}

Corresponding author: tunasalam182417@gmail.com

https://doi.org/10.14710/jksa.24.3.70-76

\section{Article Info}

Article history:

Received: $2^{\text {nd }}$ February 2021

Revised: $6^{\text {th }}$ March 2021

Accepted: $12^{\text {th }}$ March 2021

Online: $31^{\text {st }}$ March 2021

Keywords:

antimicrobial activity; silver nanoparticles; Mirabilis jalapa; Staphylococcus aureus

\begin{abstract}
The focus of this study was to compare the antimicrobial activity of silver nanoparticles (AgNPs) synthesized using ethanol extracts (AgNPE) and water extracts (AgNPA) from four o'clock flowers (Mirabilis jalapa) against Staphylococcus aureus. AgNPs were characterized by UV-Vis diffraction, FTIR, SEM, and X-rays. UV-Vis analysis showed that AgNPA has an SPR band of about $460 \mathrm{~nm}$ and $530 \mathrm{~nm}$ for AgNPE, which proves the characteristics of the absorbance area of AgNPs. SEM images of AgNPE and AgNPA show a cuboid shape with a mean diameter of 80 and $30 \mathrm{~nm}$, respectively and well dispersed. The response to the presence of polysaccharide biomolecules involved in forming AgNPs was analyzed using a Fourier transform infrared spectrometer. The result was that AgNPA and AgNPE have different reducing agents. The plant extracts, AgNPE and AgNPA, were studied for their antimicrobial activity against Staphylococcus aureus. The result was that both AgNPA and AgNPE showed good activity and showed that AgNPA with less inhibition was less effective than AgNPE.
\end{abstract}

\section{Introduction}

Nanotechnology is one of the most active and popular research fields with applications in medicine, health care, energy, safety and biotechnology. Silver nanoparticles (AgNPs) are a widespread nanotechnology material because they have many applications and various uses in various fields, particularly as antimicrobial agents. Different properties of silver nanoparticles, such as size and shape, can be synthesized by various methods. The development and synthesis of the popular AgNPs using biomaterials as bio reducing agents to form AgNP. The biomaterial method has emerged as an environmentally friendly method, offers no toxic substances and high-temperature setting, simple, fast, economical, and feasible [1].

Mirabilis jalapa belongs to the Nyctaginaceae family, known as a herbal plant, and can be found in tropical areas, especially Indonesia [2, 3]. The roots, stems, leaves, flowers and seeds of this plant can be used in many applications. Phytochemical test results prove that this plant contains flavonoids, terpenoids, tannins, saponins, and polysaccharides [4]. Several components from Mirabilis jalapa have also been isolated, including isoquinoline, rotenoids, stigmasterols, phenolic compounds, glucosides, mirabalisoic acid, and protein. There are several active components in Mirabilis jalapa that play a role in the overall serotonic mechanism and its interaction with the adrenergic system containing sitosterol, glucosides, and rotenoids [5]. In previous research, Mirabilis jalapa was used as a bio reducing agent to synthesize $\mathrm{Ag} / \mathrm{ZnO}$ nanoparticles. The formation of monometallic and bimetallic nanoparticles has also been carried out using Mirabilis jalapa leaf extract [6].

One of the essential applications of silver nanoparticles is to use these nanoparticles as an antimicrobial agent. Silver nanoparticles can be used as antimicrobial agents because they can enter the bacterial cell wall [7]. The antimicrobial activity of nanoparticles against the spectrum of gram-positive bacteria, gram- 
negative bacteria, and fungi has been proven. Achillea millefolium $L$. extract with various solvents has been used to produce silver nanoparticles and showed excellent activity against both types of bacteria [8]. S. aureus is a gram-positive bacterium and is a species of staphylococci [9]. S. aureus can affect health and is a significant cause of morbidity. This study's objective was to synthesize AgNPs using Mirabilis jalapa plant extracts with water (AgNPA) and ethanol (AgNPE) solvents and perform characterization. Also, an assessment and comparison of the antimicrobial activity of AgNPs obtained from water extract (AgNPA), and ethanol extract (AgNPE) was carried out against S. aureus.

\section{Materials and methods}

\subsection{Synthesis and characterization of AgNPs}

The Mirabilis jalapa plant (Figure 1) was obtained from Depok, West Java, Indonesia. The collected plants (stems, flowers and leaves) were thoroughly washed with distilled water to remove dust particles and dried for 10 days. The dry plant is then ground into a fine powder. $10 \mathrm{~g}$ of powder are mixed and halved for two different solvents. First, the dry plants were mixed with $100 \mathrm{~mL}$ of distilled water, and second, the dry plants were mixed with ethanol. Both were macerated for 24 hours at room temperature. The concentrate from the plant was filtered using Whatman no. 41, and the filtrate (water and ethanol extract) was used to reduce silver ions in $\mathrm{AgNO}_{3}$ solution to form AgNPs [10, 11, 12, 13, 14, 15].

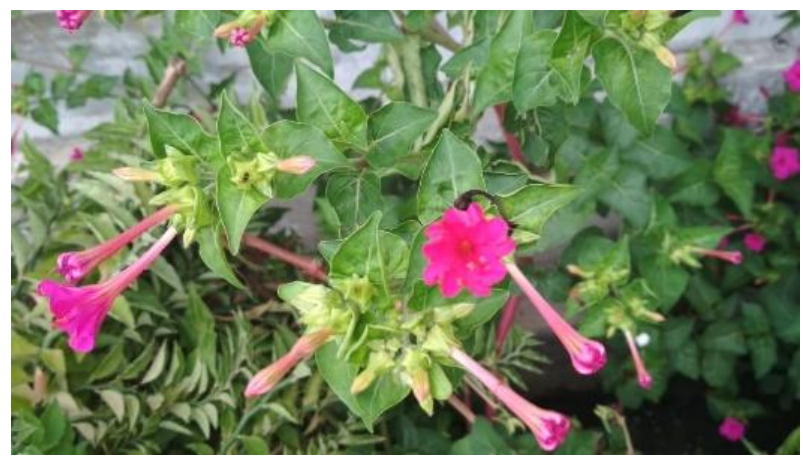

Figure 1. Typical Mirabilis jalapa plant (snapped in Depok, Jawa Barat)

$10 \mathrm{~mL}$ of $1 \mathrm{mM}$ silver nitrate was prepared in a volumetric flask. Then, 1 to $5 \mathrm{~mL}$ of ethanol plant extract and water solvent were added separately to the $\mathrm{AgNO}_{3}$ solution and kept the concentration at $1 \mathrm{mM}$. AgNPs were also synthesized with varying concentrations of $\mathrm{AgNO}_{3}(1$ to $5 \mathrm{mM}$ ) and kept the plant extract concentration constant at $1 \mathrm{~mL}$. A change indicates the reduction of $\mathrm{Ag}^{+}$ to $\mathrm{Ag}^{0}$ in the color of the solution from colorless to brown for AgNPA and green to greenish-brown for AgNPE. The presence of AgNPA and AgNPE was monitored spectrometically with a wavelength of 400 to $600 \mathrm{~nm}$ using a PG Instrument $\mathrm{T} 80+$ spectrophotometer to monitor the SPR bands of silver nanoparticles (AgNPs).

Then AgNPE and AgNPA were centrifuged at 5000 rpm for 2 hours with KHT 410 E Microcentrifuge, and the obtained nanoparticles were used for further characterization. The surface, shape, and size of the two
AgNPs were imaged by Scanning Electron Microscopy (SEM). The structure of AgNPs was determined by X-ray diffraction (XRD) using a Shimadzu X-ray Diffractometer 7000. Fourier transform infrared spectrometers were used to estimate the biomolecules of AgNPs plant extracts using the Shimadzu IRTracer-100.

\subsection{Antimicrobial activity}

The agar disc diffusion method was used to test the antimicrobial activity of AgNPA, AgNPE, and plant extracts. The bacteria used for testing was Staphylococcus aureus. HI-Media Nutrient agar (NA) was prepared by dissolving $14 \mathrm{~g}$ of nutrient agar powder with $500 \mathrm{~mL}$ of distilled water. This solution was sterilized together with all material used in autoclaved at $121^{\circ} \mathrm{C}$ for 30 minutes. Bacteria were inoculated into the Petri plate agar medium and incubated for 24 hours at $37^{\circ} \mathrm{C}$. The filter paper disks $(6 \mathrm{~mm})$ were immersed in the respective solutions containing AgNPA, AgNPE, and plant extracts. The concentration of $\mathrm{AgNO}_{3}$ was varied from 1 to $5 \mathrm{mM}$, and the volume of the plant extract was varied from 1 to $5 \mathrm{~mL}$ from a total of 20 solutions for AgNPA and AgNPE and two solutions for plant extracts (duplication for each solution). The disc containing each solution was placed on a plate and labeled. After 24 hours, the resistance zone around each disk was measured in millimeters (mm) using a scale.

\section{Results and discussion}

In this study, AgNPs were synthesized using Mirabilis jalapa plant extracts using water (AgNPA) and ethanol (AgNPE) and evaluated for their antimicrobial activity against Staphylococcus aureus.

\subsection{Synthesis of silver nanoparticles (AgNPs)}

The addition of Mirabilis jalapa plant extract, which was extracted with water and ethanol solvents, to the silver nitrate solution caused a color change of the solution from colorless to brown for AgNPA and green to greenish-brown for AgNPE (Figure 2). Before adding plant extracts, the UV-Vis spectrum showed no absorption in the 400-800 $\mathrm{nm}$ range. The color of the solution changed after stirring for 15 minutes at room temperature. This indicates the formation of silver nanoparticles confirmed by surface plasmon resonance (SPR) at $390-530 \mathrm{~nm}[8,10,12,16,17,18]$. Analysis by UV-Vis spectrophotometer showed that the SPR band at $460 \mathrm{~nm}$ is for AgNPA and $530 \mathrm{~nm}$ is for AgNPE (Figure 3). The difference in SPR bands between AgNPA and AgNPE can be shown by the different forms of AgNPs crystals $[10,19]$.

In previous studies, the SPR band at $460 \mathrm{~nm}$ showed the round shape of AgNPA and the cubic shape of AgNPE $[8,20]$. Treatment of different concentrations of silver nitrate and plant extracts was carried out to obtain optimal size and yield of AgNPs. Increasing the concentration of plant extracts increased the absorption peak's intensity by $460 \mathrm{~nm}$ for AgNPA and $530 \mathrm{~nm}$ for AgNPE. This means that the AgNPs yield increases so that it is estimated that the size of AgNPA is smaller than AgNPE (Figure 4). As the silver nitrate concentration increased, the absorption peak's intensity at $460 \mathrm{~nm}$ for 
AgNPA also increased, and there was a slight increase in the absorption peak at $530 \mathrm{~nm}$ for AgNPE (Figure 5). Increasing the concentration of silver nitrate and plant extracts increased the yield of AgNPA but only slightly increased the yield of AgNPE. Figure 3, Figure 4, and Figure 5 show that AgNPA has smaller particles than AgNPE because AgNPA has more absorption peaks at 460 $\mathrm{nm}$ than at $530 \mathrm{~nm}$. The SPR band at a lower wavelength indicates a smaller particle size, and this means that it is more effective as an antimicrobial [16].
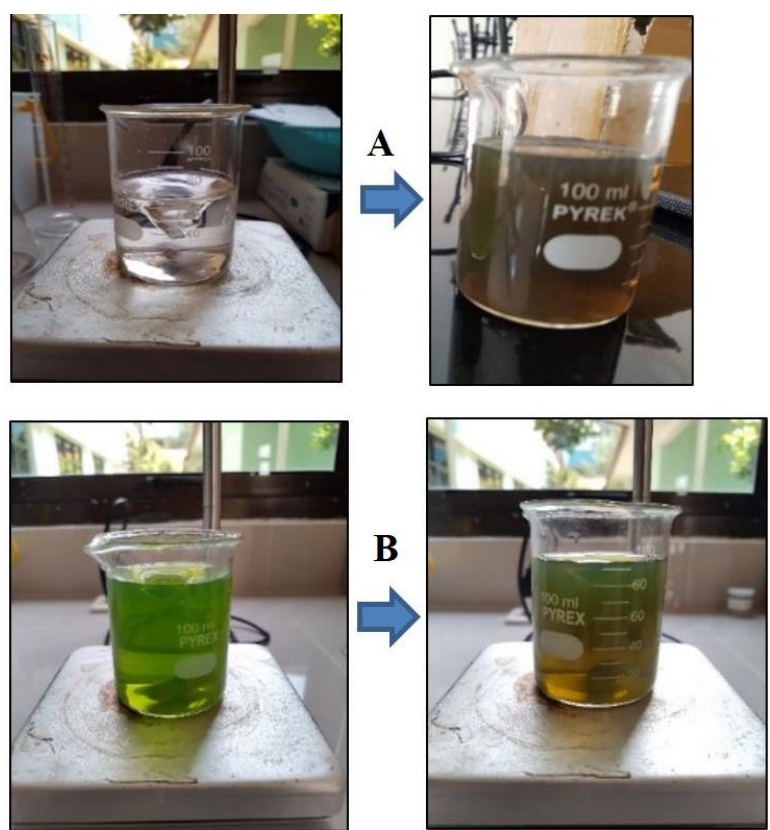

Figure 2. Digital optical images of $\mathrm{AgNO}_{3}$ and plant extract mixture (a) water extract and $\mathrm{AgNO}_{3}$ (b) ethanol extract and $\mathrm{AgNO}_{3}$
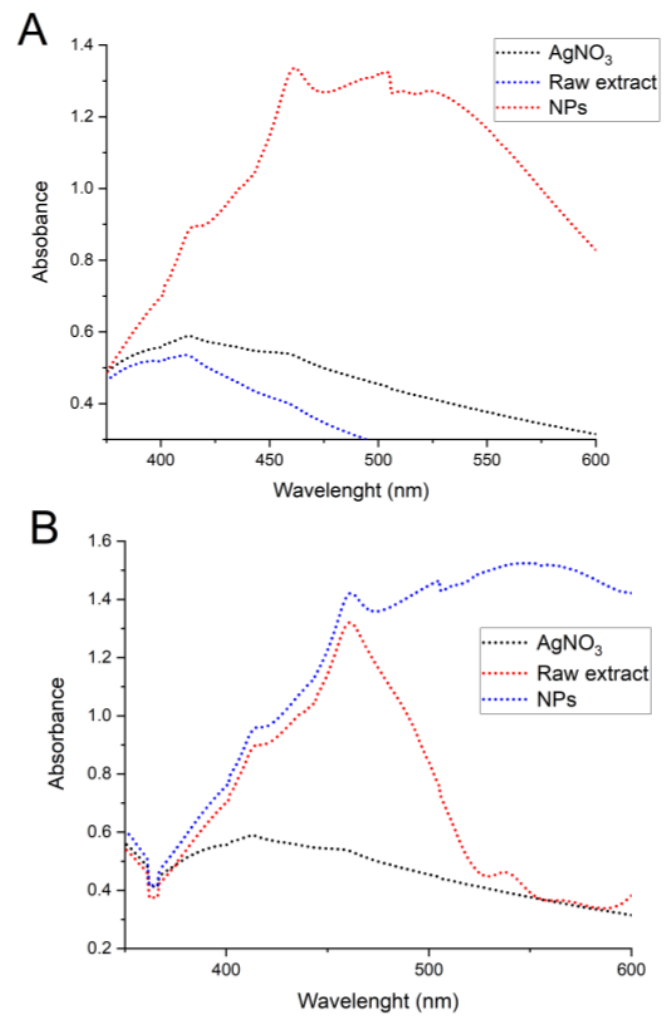

Figure 3. UV-Vis spectra of (a) AgNPA with SPR band at $460 \mathrm{~nm}$ and (b) AgNPE with SPR band at $530 \mathrm{~nm}$
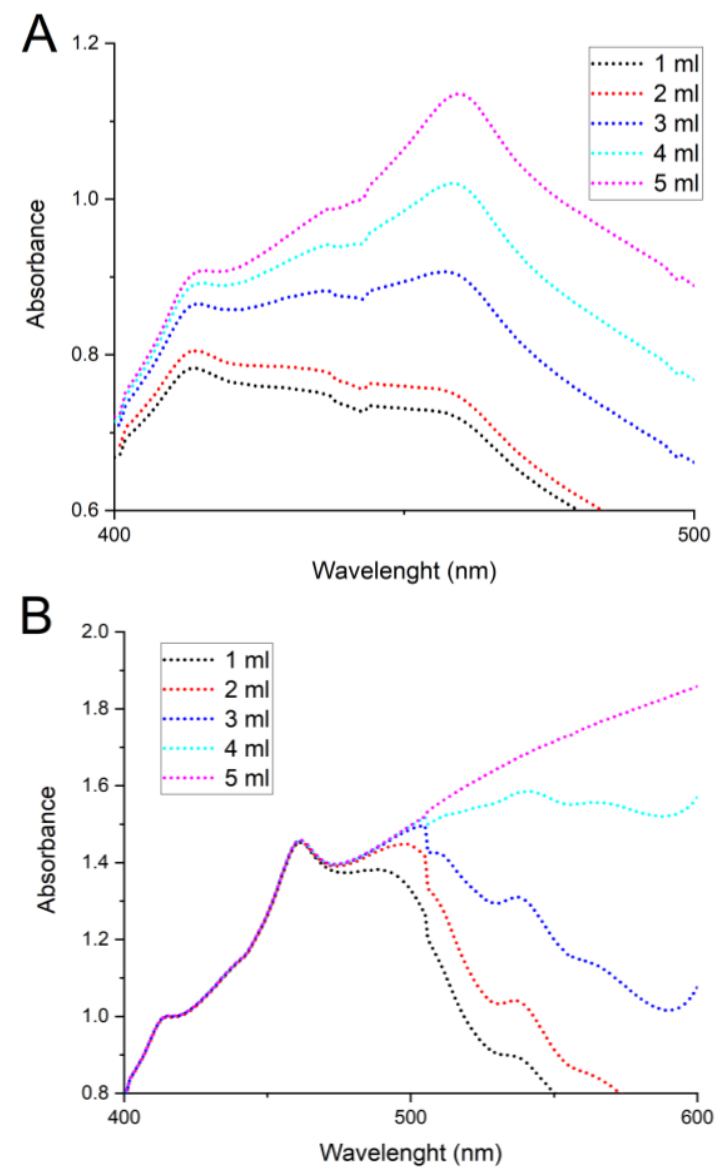

Figure 4. UV-Vis spectra of silver nanoparticles (AgNPs) with different concentration of plant extract (1-5 mL) using (a) water (AgNPA) (b) ethanol (AgNPE)

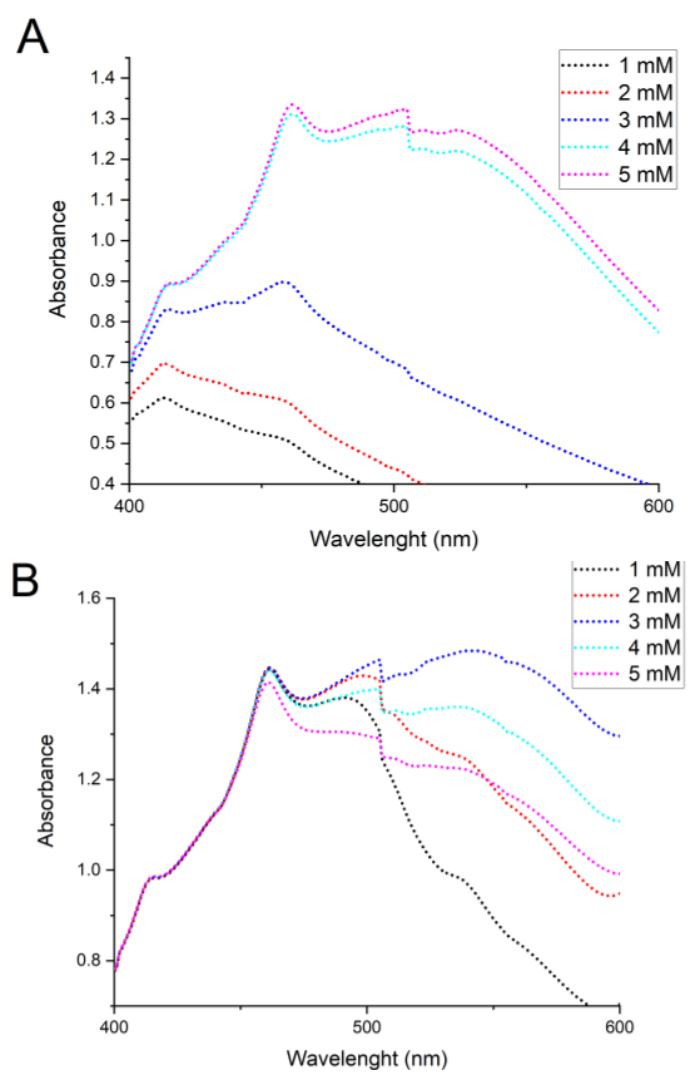

Figure 5. UV-Vis spectra of silver nanoparticles (AgNPs) with different concentration of $\mathrm{AgNO}_{3}(1-5 \mathrm{mM})$ using (a) water extract (AgNPA) (b) ethanol extract (AgNPE) 


\subsection{Morphology, size, and structure of silver nanoparticles (AgNPs)}

Analysis by SEM shows that AgNPA and AgNPE are cubic, respectively (Figure 6). The mean particle size was $80 \mathrm{~nm}$ for AgNPE and $30 \mathrm{~nm}$ for AgNPA. Whereas the XRD patterns of AgNPA and AgNPE show a face-centered crystal structure, as confirmed in Figure 6, with the peak of AgNPA being stronger than AgNPE. This indicates that AgNPA has a higher crystallinity. All peaks have typical characteristics for silver metal with FCC symmetry and are matched to JCPDS No.00-004-0783 [21]. This is characterized by peaks [111], [200], [220], and [311], which prove that silver nanoparticles were successfully synthesized. The unknown peaks (marked with an asterisk) probably originate from the bio-organic phase on the surface of the AgNPs [13, 22, 23]. Figure 7 shows that AgNPA has a smaller size than AgNPE. Previous studies have suggested that smaller nanoparticles are more useful as antibacterial agents [24].

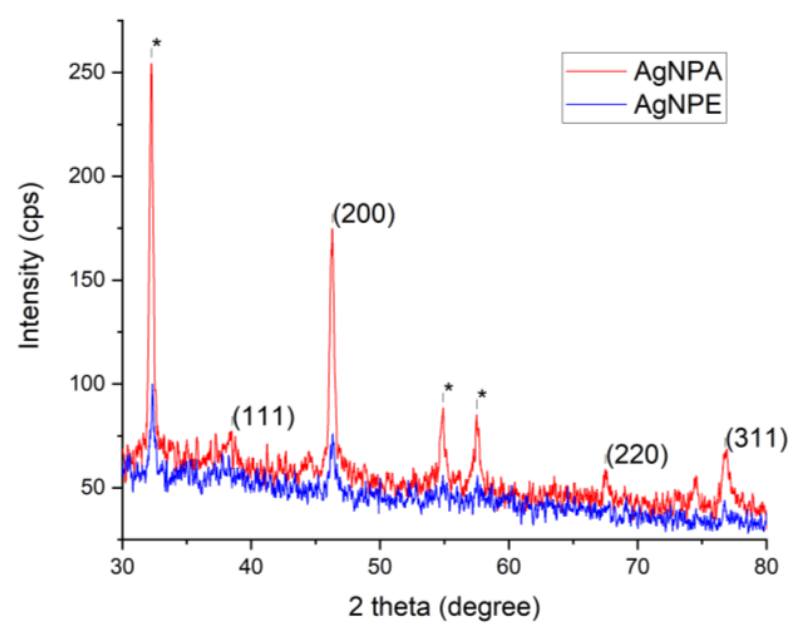

Figure 6. XRD patterns of AgNPA and AgNPE
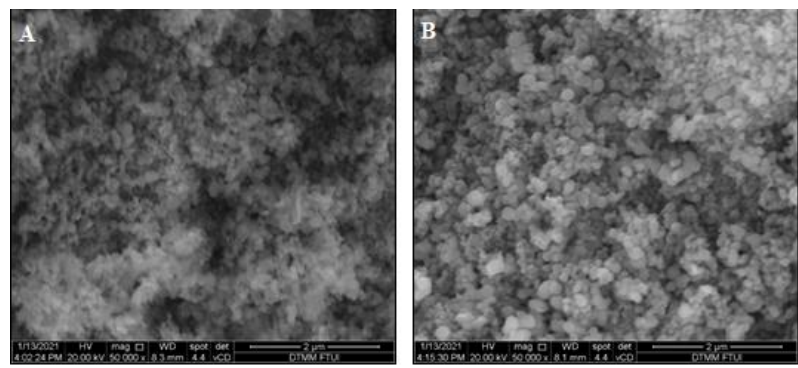

Figure 7. SEM images of silver nanoparticles (a) AgNPA (b) AgNPE

3.3. Identification of possible biomolecules involved in of synthesis silver nanoparticles (AgNPs)

FTIR analysis showed that a peak at $1650 \mathrm{~cm}^{-1}$ corresponded to the $-\mathrm{C}=\mathrm{C}$ - band, while the $-\mathrm{OH}$ band was found at $3527 \mathrm{~cm}^{-1}$ for AgNPA (Figure 8). The functional groups for AgNPA represent the aromatic groups of phenolic compounds and the hydroxyl groups of polyphenols such as terpenoids and aromatic alkenes. AgNPE showed several peaks at 1570, 2286, 2343, 2389, and $3158 \mathrm{~cm}^{-1}$ corresponding to the $-\mathrm{C}=\mathrm{C}$ - aromatic phenolic and -OH hydroxyl groups of the polyphenol. The peaks 2286, 2343, and $2389 \mathrm{~cm}^{-1}$ represent alkyne (Figure 8). In previous studies, the hydroxyl group -OH of the metabolite Mirabilis jalapa, which involved bioreduction, was known as a polysaccharide [25]. Meanwhile, these results indicate that AgNPA and AgNPE contain different phytochemicals from extracts that involve bioreduction. The difference in the size and shape of the nanoparticles derived from different plant extracts may be due to different functional groups in the extracts.

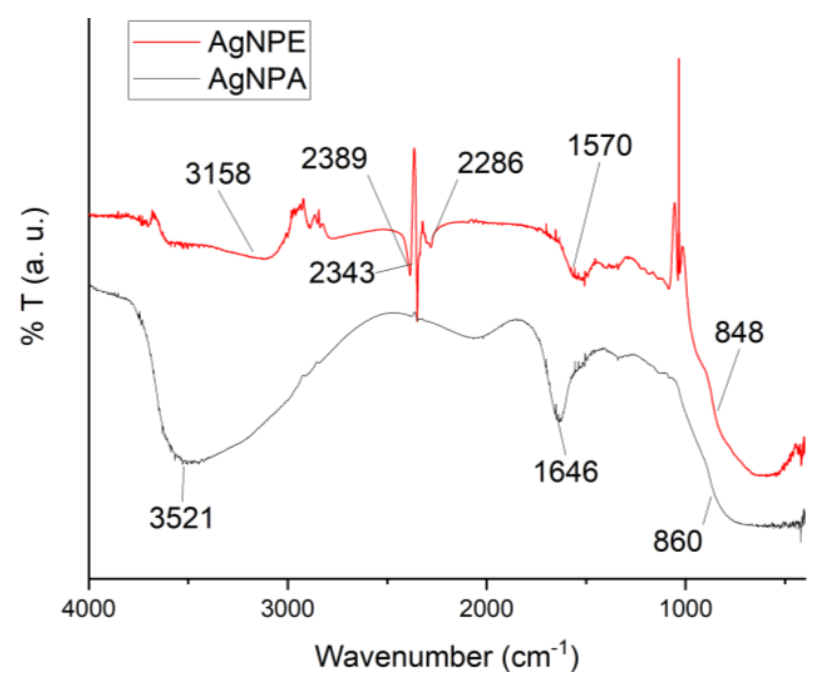

Figure 8. FTIR spectra of AgNPs

\subsection{Antibacterial activity}

Silver nanoparticles are known as antibacterial agents and are used in various industries. However, silver is restricted as a chemical antibacterial agent in the medicinal industry. This problem has an alternative solution using green synthesis to form silver nanoparticles (AgNPs). Antibacterial activity of AgNPs in vitro was carried out by the disc diffusion method, and the results are shown in Table 1, Figure 9, and Figure 10.

Table 1. Antimicrobial activity of AgNPE and AgNPA against $S$. aureus

\begin{tabular}{|c|c|c|c|}
\hline \multirow[t]{2}{*}{ No } & \multicolumn{2}{|c|}{$\begin{array}{c}\text { Component AgNPE (No. 1-10) and } \\
\text { AgNPA (No. 11-20) }\end{array}$} & \multirow{2}{*}{$\begin{array}{c}\text { Zone of } \\
\text { inhibition } \\
(\mathrm{mm})\end{array}$} \\
\hline & $\mathrm{AgNO}_{3}(\mathrm{mM})$ & Extract $(\mathrm{mL})$ & \\
\hline 1 & 1 & 1 & NZ \\
\hline 2 & 2 & 1 & NZ \\
\hline 3 & 3 & 1 & 7 \\
\hline 4 & 4 & 1 & 7 \\
\hline 5 & 5 & 1 & NZ \\
\hline 6 & 1 & 1 & 5 \\
\hline 7 & 1 & 2 & 6 \\
\hline 8 & 1 & 3 & 7 \\
\hline 9 & 1 & 4 & 7 \\
\hline 10 & 1 & 5 & 5 \\
\hline 11 & 1 & 1 & 7 \\
\hline 12 & 2 & 1 & NZ \\
\hline 13 & 3 & 1 & 7 \\
\hline 14 & 4 & 1 & 5 \\
\hline 15 & 5 & 1 & 6 \\
\hline 16 & 1 & 1 & 7 \\
\hline 17 & 1 & 2 & 11 \\
\hline 18 & 1 & 3 & 5 \\
\hline 19 & 1 & 4 & 6 \\
\hline 20 & 1 & 5 & 6 \\
\hline 21 & \multicolumn{2}{|c|}{ Control } & NZ \\
\hline 24 & \multicolumn{2}{|c|}{ Control } & $\mathrm{NZ}$ \\
\hline
\end{tabular}


From Table 1, it can be ascertained that by varying the concentration of $\mathrm{AgNO}_{3}$, S. aureus inhibition is more effective than varying the concentration of plant extracts in the synthesis of AgNPs. AgNPE has more "NZ" (zoneless) than AgNPA, which means it has lower antibacterial activity, especially in S. aureus. The plant extract was used as a control and showed no antibacterial activity against $S$. aureus. The inhibition of $S$. aureus can be determined because its walls are not covered by an outer lipid membrane as is found in gram-negative [14]. In the literature, sensitivity to AgNPs has been reported [26]. Besides, the efficiency of AgNPs depends on the number and size of AgNPs to access the bacterial cell wall. Smaller AgNPs have better access to bacteria [24]. The smaller size of the AgNPs has a wider surface area resulting in higher antibacterial activity [27]. Our results support this idea AgNPA is smaller in size than AgNPE and generates more inhibition. There are many mechanisms for AgNPs as antibacterial agents. AgNPs can damage bacterial cell membranes or touch the surface of bacteria [28, 29]. AgNPs can make intense contact with bacterial cell walls because of their larger surface area, smaller size, and different electrostatic charges [7]. Another idea of the antibacterial activity of AgNPs is that the AgNPs suspension occurs in solution. Significant investigations have revealed how interactions between AgNPs and bacterial cells occur, in which $\mathrm{Ag}$ + ions are responsible for producing an inhibitory effect against bacterial strains [30].

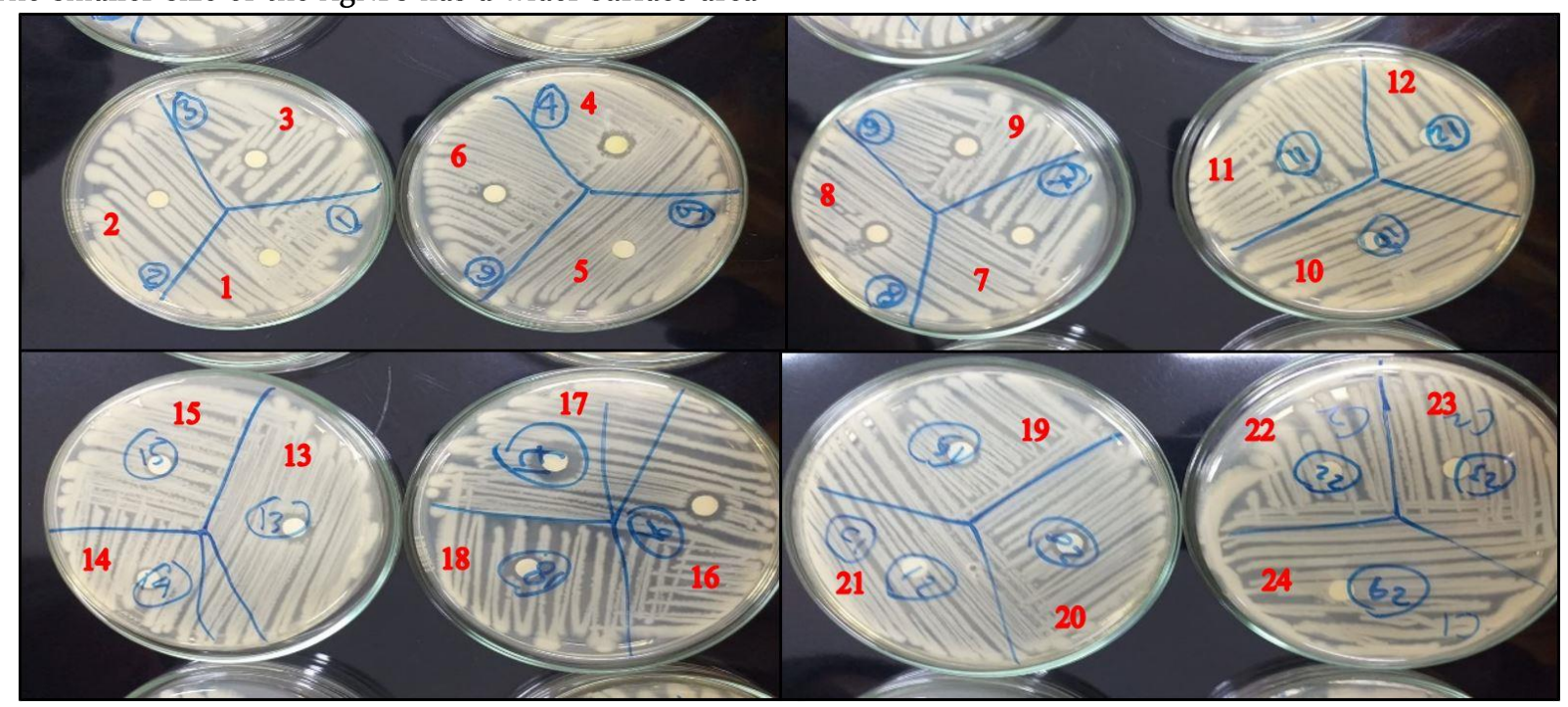

Figure 9. Plates showing the antimicrobial activity of silver nanoparticles (AgNPs) using different concentration of $\mathrm{AgNO}_{3}(1-5 \mathrm{mM})$ and different concentration of plant extract (1-5 mL) against S. aureus using water extract (AgNPA) and ethanol extract (AgNPE)

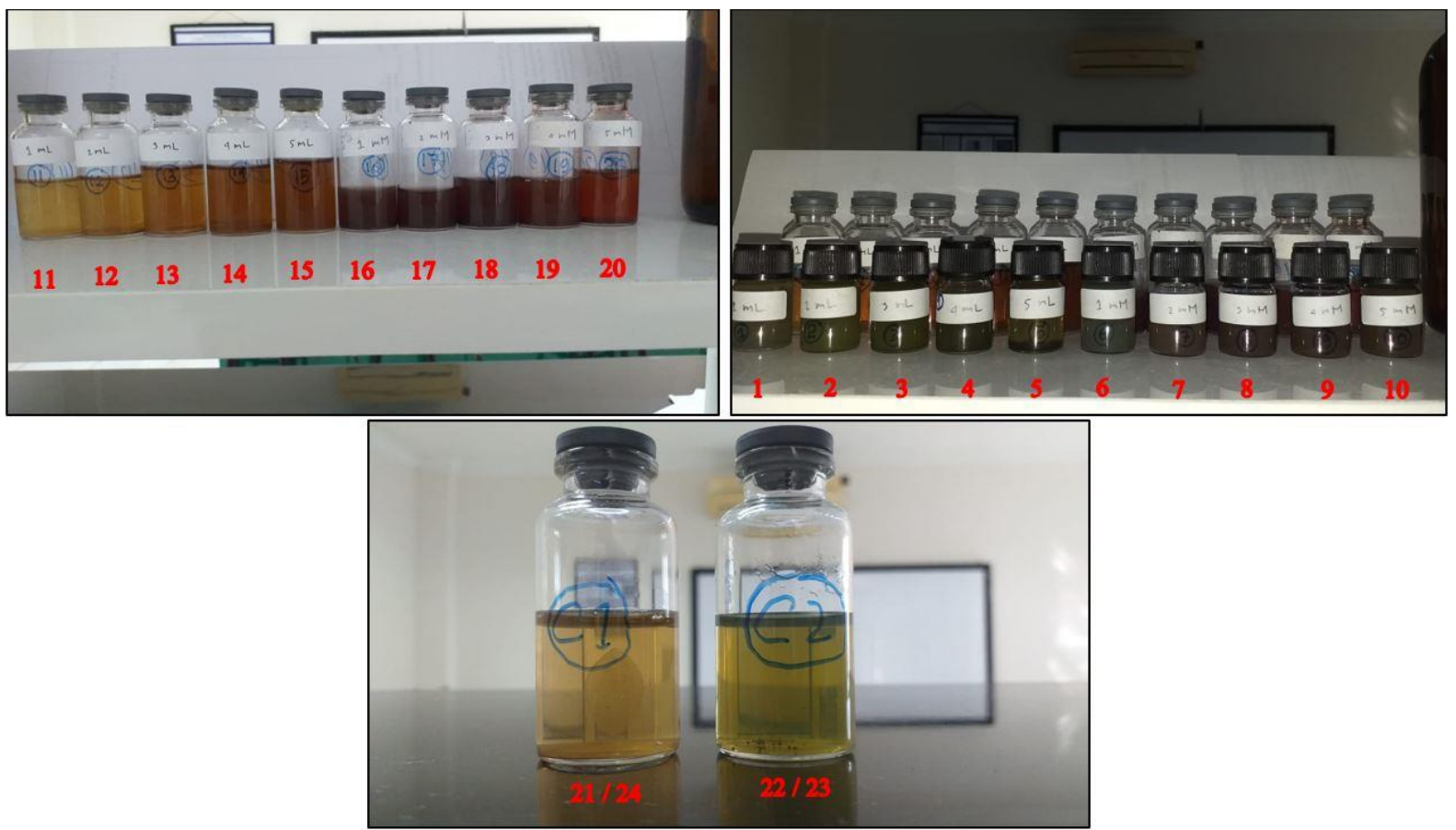

Figure 10. Digital optical images of silver nanoparticles (AgNPs) using different concentration of $\mathrm{AgNO}_{3}(1-5 \mathrm{mM})$ and different concentration of plant extract (1-5 mL) using (a) water (AgNPA) and (b) ethanol (AgNPE) 


\section{Conclusion}

Silver nanoparticles (AgNPs) have been successfully synthesized from Mirabilis jalapa plant extract from two different solvents as a green synthesis that is non-toxic, cost-effective, and environmentally friendly. AgNPs from water extract (AgNPA) Mirabilis jalapa had a smaller size than AgNPs from ethanol extract (AgNPE) estimated by UV-Vis and SEM analysis. Both AgNPs had characteristic peaks of silver nanoparticles and showed AgNPA to have a higher crystallinity than AgNPE. The antimicrobial activity of AgNPA and AgNPE has good activity, and AgNPA has a slightly more effective inhibitory power against S. aureus than AgNPE due to its smaller size and larger surface area for contact with cell bacteria. Different sizes and surface areas can be affected by different biomolecules reducing AgNPs and analyzed by FTIR.

\section{References}

[1] Chella Purushothaman Devatha, Arun K. Thalla, Chapter 7 - Green Synthesis of Nanomaterials, in: S. Mohan Bhagyaraj, O.S. Oluwafemi, N. Kalarikkal, S. Thomas (Eds.) Synthesis of Inorganic Nanomaterials, Woodhead Publishing, 2018, https://doi.org/10.1016/B978-0-08-101975-7.00007-5

[2] Ullah Naveed, Ahmad Habib, Asif Afzal Haq, Abdul Qadar Khan, Anwar Rabia, Antibacterial activities of genetic variants of Mirabilis jalapa, Pharmacognosy Journal, 2, 7, (2010), 181-184

https://doi.org/10.1016/S0975-3575(10)80089-6

[3] Chifundera Kusamba, Kizungu Byamana, Wa Mpoyi Mbuyi, Antibacterial activity of Mirabilis jalapa seed powder, Journal of Ethnopharmacology, 35, 2, (1991), 197-199 https://doi.org/10.1016/0378-8741(91)90073-M

[4] Jyotchna Gogoi, Khonamai Sewa Nakhuru, Rudragoud S. Policegoudra, Pronobesh Chattopadhyay, Ashok Kumar Rai, Vijay Veer, Isolation and characterization of bioactive components from Mirabilis jalapa L. radix, Journal of Traditional and Complementary Medicine, 6, 1, (2016), 41-47

https://doi.org/10.1016/j.jtcme.2014.11.028

[5] Kazuko Aoki, Alma Rosa Cortés, María del Carmen Ramírez, Martín Gómez-Hernández, Francisco J. López-Muñoz, Pharmacological study of antispasmodic activity of Mirabilis jalapa Linn flowers, Journal of Ethnopharmacology, 116, 1, (2008), 96-101 https://doi.org/10.1016/j.jep.2007.11.004

[6] Sumbal, Asifa Nadeem, Sania Naz, Joham Sarfraz Ali, Abdul Mannan, Muhammad Zia, Synthesis, characterization and biological activities of monometallic and bimetallic nanoparticles using Mirabilis jalapa leaf extract, Biotechnology Reports, 22, (2019), e00338 https://doi.org/10.1016/j.btre.2019.e00338

[7] Shao Feng Chen, Jian Ping Li, Kun Qian, Wei Ping $\mathrm{Xu}$, Yang Lu, Wei Xin Huang, Shu Hong Yu, Large scale photochemical synthesis of $\mathrm{M} @ \mathrm{TiO} 2$ nanocomposites $(\mathrm{M}=\mathrm{Ag}, \mathrm{Pd}, \mathrm{Au}, \mathrm{Pt})$ and their optical properties, $\mathrm{CO}$ oxidation performance, and antibacterial effect, Nano Research, 3, 4, (2010), 244-255 https://doi.org/10.1007/s12274-010-1027-z
[8] Huma Yousaf, Ansar Mehmood, Khawaja Shafique Ahmad, Muhammad Raffi, Green synthesis of silver nanoparticles and their applications as an alternative antibacterial and antioxidant agents, Materials Science and Engineering: C, 112, (2020), 110901 https://doi.org/10.1016/j.msec.2020.110901

[9] Mitchell L. Cohen, Staphylococcus aureus: Biology, mechanisms of virulence, epidemiology, The Journal of Pediatrics, 108, 5, Part 2, (1986), 796-799 https://doi.org/10.1016/S0022-3476(86)80747-8

[10] Adewumi Oluwasogo Dada, Folahan Amoo Adekola, Fehintoluwa Elizabeth Dada, Adunola Tabitha Adelani-Akande, Micheal Oluwasesan Bello, Chidiogo Rita Okonkwo, Adejumoke Abosede Inyinbor, Abimbola Peter Oluyori, Adeniyi Olayanju, Kolawole Oluseyi Ajanaku, Charles Oluwaseun Adetunji, Silver nanoparticle synthesis by Acalypha wilkesiana extract: phytochemical screening, characterization, influence of operational parameters, and preliminary antibacterial testing, Heliyon, 5, 10, (2019), e02517 https://doi.org/10.1016/j.heliyon.2019.e02517

[11] Is Fatimah, Nur Afisa Lintang Mutiara, Biosythesis of silver nanoparticles using Putri Malu (Mimosa pudica) leaves extract and microwave irradiation method, Molekul, 11, 2, (2016), 288-298 http://dx.doi.org/10.20884/1.jm.2016.11.2.221

[12] M. Gopalakrishnan, A. Sheenu, Binny Varghese, J. Dharani, S. Saranya, A Green Approach for Synthesis and Characterization of Silver Nanoparticlesand Their Anti-Microbial Activity, Rasayan Journal of Chemistry, 12, 3, (2019), 1072-1076 https://doi.org/10.31788/RJC.2019.1235136

[13] Mahendran Vanaja, Gurusamy Annadurai, Coleus aromaticus leaf extract mediated synthesis of silver nanoparticles and its bactericidal activity, Applied Nanoscience, 3, 3, (2013), 217-223 https://doi.org/10.1007/s13204-012-0121-9

[14] Aftab Ahmad, Fatima Syed, Akram Shah, Zahid Khan, Kamran Tahir, Arif Ullah Khan, Qipeng Yuan, Silver and gold nanoparticles from Sargentodoxa cuneata: synthesis, characterization and antileishmanial activity, RSC Advances, 5, 90, (2015), 73793-73806 https://doi.org/10.1039/C5RA13206A

[15] Tentu Nageswara Rao, Riyazuddin, P. Babji, Naushad Ahmad, Rais Ahmad Khan, Iftekhar Hassan, Syed Ali Shahzad, Fohad Mabood Husain, Green synthesis and structural classification of Acacia nilotica mediated-silver doped titanium oxide (Ag/TiO2) spherical nanoparticles: Assessment of its antimicrobial and anticancer activity, Saudi Journal of Biological Sciences, 26, 7, (2019), 1385-1391

https://doi.org/10.1016/j.sjbs.2019.09.005

[16] Shakeel Ahmed, Mudasir Ahmad, Babu Lal Swami, Saiqa Ikram, A review on plants extract mediated synthesis of silver nanoparticles for antimicrobial applications: A green expertise, Journal of Advanced Research, 7, 1, (2016), 17-28

https://doi.org/10.1016/j.jare.2015.02.007

[17] Vudagandla Sreenivasulu, Nadavala Siva Kumar, M. Suguna, Mohammad Asif, Ebrahim Al-Ghurabi, Z. Huang, Z. Zhen, Biosynthesis of Silver Nanoparticles using Mimosa Pudica Plant root extract: Characterization, Antibacterial Activity and Electrochemical Detection of Dopamine, 
International Journal of Electrochemical Science, 11, (2016), 9959-9971

https://doi.org/10.20964/2016.12.69

[18] Shakeel Ahmed, Saifullah, Mudasir Ahmad, Babu Lal Swami, Saiqa Ikram, Green synthesis of silver nanoparticles using Azadirachta indica aqueous leaf extract, Journal of Radiation Research and Applied Sciences, 9, 1, (2016), 1-7 https://doi.org/10.1016/j.jrras.2015.06.006

[19] Sepideh Hamedi, Seyed Abbas Shojaosadati, Rapid and green synthesis of silver nanoparticles using Diospyros lotus extract: Evaluation of their biological and catalytic activities, Polyhedron, 171, (2019), 172-180 https://doi.org/10.1016/j.poly.2019.07.010

[20] Gianluca Calestani, Introduction to crystallography, in: P.W. Hawkes, P.G. Merli, G. Calestani, M. VittoriAntisari (Eds.) Advances in Imaging and Electron Physics, Elsevier, 2002, https://doi.org/10.1016/S1076-5670(02)80060-X

[21] Mohsen Zargar, Azizah Abdul Hamid, Fatima Abu Bakar, Mariana Nor Shamsudin, Kamyar Shameli, Fatemeh Jahanshiri, Farah Farahani, Green Synthesis and Antibacterial Effect of Silver Nanoparticles Using Vitex Negundo L, Molecules, 16, 8, (2011), 6667-6676 https://doi.org/10.3390/molecules16086667

[22] Bulent Ulug, M. Haluk Turkdemir, Ahmet Cicek, Ahmet Mete, Role of irradiation in the green synthesis of silver nanoparticles mediated by fig (Ficus carica) leaf extract, Spectrochimica Acta Part A: Molecular and Biomolecular Spectroscopy, 135, (2015), 153-161 https://doi.org/10.1016/j.saa.2014.06.142

[23] Daizy Philip, Biosynthesis of $\mathrm{Au}, \mathrm{Ag}$ and $\mathrm{Au}-\mathrm{Ag}$ nanoparticles using edible mushroom extract, Spectrochimica Acta Part A: Molecular and Biomolecular Spectroscopy, 73, 2, (2009), 374-381 https://doi.org/10.1016/j.saa.2009.02.037

[24] Tracy L. Collins, Elizabeth A. Markus, Daniel J. Hassett, Jayne B. Robinson, The Effect of a Cationic Porphyrin on Pseudomonas aeruginosa Biofilms, Current Microbiology, 61, 5, (2010), 411-416 https://doi.org/10.1007/s00284-010-9629-y

[25] Palaniselvam Kuppusamy, Mashitah M. Yusoff, Gaanty Pragas Maniam, Natanamurugaraj Govindan, Biosynthesis of metallic nanoparticles using plant derivatives and their new avenues in pharmacological applications - An updated report, Saudi Pharmaceutical Journal, 24, 4, (2016), 473-484 https://doi.org/10.1016/j.jsps.2014.11.013

[26] Tahir Rasheed, Muhammad Bilal, Hafiz M. N. Iqbal, Chuanlong Li, Green biosynthesis of silver nanoparticles using leaves extract of Artemisia vulgaris and their potential biomedical applications, Colloids and Surfaces B: Biointerfaces, 158, (2017), 408-415 https://doi.org/10.1016/j.colsurfb.2017.07.020

[27] Libor Kvítek, Aleš Panáček, Jana Soukupová, Milan Kolář, Renata Večeřová, Robert Prucek, Mirka Holecová, Radek Zbořil, Effect of Surfactants and Polymers on Stability and Antibacterial Activity of Silver Nanoparticles (NPs), The Journal of Physical Chemistry C, 112, 15, (2008), 5825-5834 https://doi.org/10.1021/jp711616v
[28] Veronica Lazar, Quorum sensing in biofilms - How to destroy the bacterial citadels or their cohesion/power?, Anaerobe, 17, 6, (2011), 280-285 https://doi.org/10.1016/j.anaerobe.2011.03.023

[29] Saravanan Periasamy, Hwang-Soo Joo, Anthony C. Duong, Thanh-Huy L. Bach, Vee Y. Tan, Som S. Chatterjee, Gordon Y. C. Cheung, Michael Otto, How Staphylococcus aureus biofilms develop their characteristic structure, Proceedings of the National Academy of Sciences, 109, 4, (2012), 1281 https://doi.org/10.1073/pnas.1115006109

[30] Daeyeon Lee, Robert E. Cohen, Michael F. Rubner, Antibacterial Properties of Ag Nanoparticle Loaded Multilayers and Formation of Magnetically Directed Antibacterial Microparticles, Langmuir, 21, 21, (2005), 9651-9659 https://doi.org/10.1021/la0513306 